\title{
KOMUNITAS LAMUN DI PERAIRAN PESISIR PULAU YAMDENA, KABUPATEN MALUKU TENGGARA BARAT
}

\author{
Rene Ch. Kepel ${ }^{1}$ dan Sandra Baulu ${ }^{2}$ \\ ${ }^{1}$ Program Studi Manajemen Sumberdaya Perairan, \\ Fakultas Perikanan dan IImu Kelautan, UNSRAT, Manado 95115. \\ ${ }^{2}$ Pemerintah Kabupaten Maluku Tenggara Barat
}

\begin{abstract}
This study was aimed at identifying the seagrass, and knowing the seagrass community structure in the coastal waters of Yamdena Island, West Southeast Maluku. This study was carried out from July to September 2007. The highest density was shown by $C$. rotundata in Olilit, T. hemprichii in Lauran and Kabiarat, and E. acorroides in Kabiarat and Watmasa. Furthermore, the highest abundance of seagrass occurred by $C$. rotundata in Olilit, $H$. pinifolia in Lauran, $T$. hemprichii in Kábiarat, and $E$. acoroides in Watsama. The highest occurrence was shown by $C$. rafundata in Olilit, $E$. acoroides in Lauran, $T$. hemprichii in Kabiarat and Lauran, and $H$ y pinifolia dan $H$. ovalis in Watmasa.
\end{abstract}

Keywords: Seagrass, community, Yamdena Island, West Southeast Maluku.

\section{PENDAHULUAN}

Lamun (seagrass) adalah satu-satunya kelompok tumbuhan berbunga yang hidup secara tetap di lingkungan perairan pantai yang dangkal dan merupakan kunci dalam peranan ekologis (Den Hartog) 1970). Lamun tersebar luas di perairan pantai di seluruh dunia yang substratoserta kedalamannya cocok bagi pertumbuhannya. Biasanya komunitas lamun tumbuh berbatasan dengan komunitas bakau di tepi pantai dan komunitas terumbu karang di laut.

Kebanyakan spesies lamun mempunyai morfologi luaryyang secara kasar hampir serupa karena memiliki rhizoma, daun dan akar. Perbedaannya dalam hal pemisahan strukturr morfologi daun, tangkai, akar dan struktur reproduksi (bunga dan buah) Lamun memiliki daun-daun panjang, tipis dan mirip pita yang mempunyai saluran-saluran air serta bentuk pertumbuhannya monopodial (Nybakken, 1992). Bagian lamun yang tumbuh menjalar di bawah permukaan dasar laut disebut rhizoma (Dahuri $d k k, 1996)$. Semua lamun mempunyai rhizoma yang mirip silinder dan sebagian besar tidak berkayu, kecuali pada Thalassodendron ciliatum. Lamun ini memiliki rhizoma tumbuh pula akar dan beberapa cabang pendek yang tumbuh tegak untuk menahan daun-daunnya.

Y Purwanto dan Suryadi Putra (1984) dalam Ongkers (1990) mengemukakan bahwa komunitas lamun mempunyai peran ganda dalam pengontrolan atau perubahan ekosistem perairan, yaitu sebagai makanan hewan air, habitat biota epifit, produsen serasah melalui dekomposisi, pendaur zat organik maupun anorganik dan penangkap serta stabilisator dasar perairan.

Kabupaten Maluku Tenggara Barat memiliki sumberdaya laut, termasuk lamun. Untuk itu sangat diperlukan suatu kegiatan penelitian menyangkut potensi sumberdaya lamun yang meliputi struktur komunitas sumberdaya tersebut. Tujuan yang ingin dicapai dalam penelitian ini yaitu identifikasi lamun serta struktur komunitasnya yang ada di perairan Kabupaten Maluku Tenggara Barat, Provinsi Maluku, khususnya di Pulau Yamdena.

\section{METODOLOGI PENELITIAN}

Penelitian ini berlangsung dari JuliSeptember 2007. Tempat pelaksanaan penelitian yaitu perairan Kabupaten Maluku Tenggara Barat di 4 lokasi pengamatan di Pulau Yamdena yaitu Desa Olilit, Desa Lauran, Desa Kabiarat, dan Desa Watmasa. 
Pengambilan sampel alga yang terdapat di perairan Pulau Yamdena dilakukan dengan menggunakan metode garis transek (line transect) dengan teknik sampling kuadrat (Krebs, 1999). Pengambilan sampel dilakukan pada 4 lokasi yang berbeda serta penempatan transek dibagi menjadi tiga transek sepanjang $100 \mathrm{~m}$ yang diletakkan tegak lurus terhadap garis pantai. Pengambilan sampel dilakukan pada saat air surut (pasang tinggi, surut terendah), agar sampel alga dapat terlihat dengan jelas dan dengan mudah dilakukan pengambilan sampel.

Di setiap penempatan garis transek pada masing-masing lokasi penelitian diletakkan 10 buah kuadrat dengan jarak antar kuadrat $10 \mathrm{~m}$ dan jarak antar transek $50 \mathrm{~m}$. Kemudian, semua individu makrofita laut yang terdapat di dalam kuadrat diangkat dari substratnya dan dimasukkan ke dalam kantong plastik yang telah diberi label.

Sampel yang telah diambil, sebelum dibawa ke laboratorium untuk diidentifikasi, dicuci dan dibersihkan terlebih dahulu dari kotoran yang menempel, kemudian diberi larutan formalin $4 \%$ sebagai pengawet untuk menjaga agar sampel tidak mudah rusak. Sampel yang telah bersih tersebut dipisahkan menurut spesies masing-masing, selanjutnya spesies-spesies tersebut dibawa ke laboratorium untuk diidentifikasi.

Untuk analisis data, formula yang digunakan yaitu analisis kepadătan dan kepadatan relatif dengan ménggunakan formula menurut Krebs (1999) yaitu:

a. Kepadatan spesies $\rightarrow$ jumlah individu tiap spesies per luas wilayah contoh $\left(\mathrm{m}^{2}\right)$

Kepadatan relatif = jumlah individu tiap spesies per jumlah individu seluruh spesies $x 100 \%$

b. Kelimpahan spesies = jumlah individu - spesles A per jumlah kotak pengamatan tempat spesies A berada

Kelimpahan relatif $=$ kelimpahan suatu spesies per kelimpahan semua spesies $x 100 \%$

c. Frekuensi kehadiran = jumlah kotak pengamatan pada suatu spesies ditemukan per total kotak pengamatan Frekuensi Kehadiran relatif $=$ frekuensi kehadiran suatu spesies per frekuensi kehadiran semua spesies x $100 \%$

\section{HASIL DAN PEMBAHASAN}

Dari hasil identifikasi spesies lamun di Olilit, Lauran, Kabiarat, dan Watmasa teridentifikasi sebanyak 7 spesies yaitu Enhalus acoroides, Halophila ovalis, Halodule pinifolia, Thalassia hemprichii, Syringodium isoetifolium, Cymodocea rotundata dan Cymodocea serrulata.

\section{Kepadatan Spesies Lamun}

Berdasarkan hasil analisis kepadatan lamun di 4 lokasi pengamatan di Pulau Yamdena menunjukkan bahwa dí Olilit memiliki 6 spesies yaitu S. isoetifolium, $H$. ovalis, $C$. rotundata, $C$. serrulata, $T$. hemprichii dan $H$. pinifolia. Spesies yang memiliki kepadatan tatnggi adalah $C$. rotundata dengan nilas kepadatan sebesar $27,75 \mathrm{ind} / \mathrm{m}^{2}(26,96 \%)$, kepadatan terendah dimiliki oleh $C$. serrulata dengan nilai $7,32 / \mathrm{m}^{2}(7,12 \%)$ (Gambar 1).

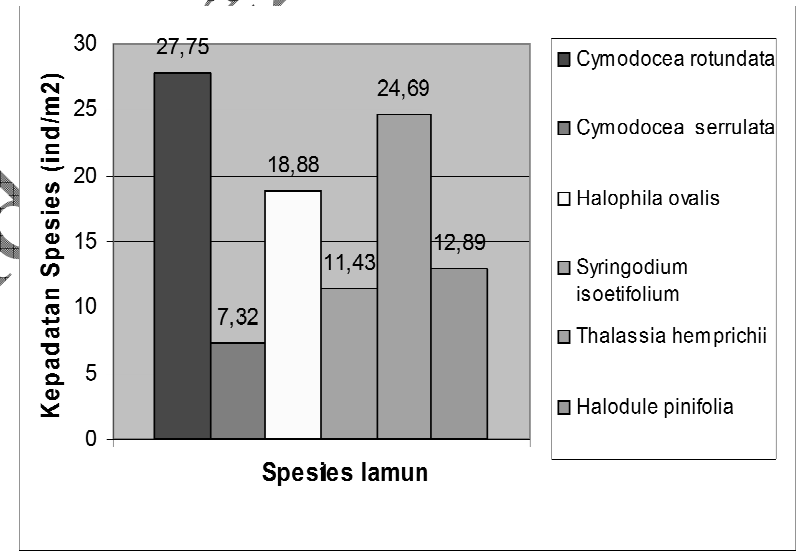

Gambar 1. Kepadatan Jenis-jenis lamun di Olilit.

Di Lauran dengan jumlah 3 spesies yaitu $E$. acoroides, $T$. hemprichii dan $H$. pinifolia dengan kepadatan tertinggi dimiliki oleh $T$. hemprichii dan nilai kepadatan sebesar $3,33 \mathrm{ind} / \mathrm{m}^{2}(53,010 \%)$, sedangkan kepadatan terendah dimiliki oleh $H$. pinifolia dengan nilai kepadatan 1,05 ind $/ \mathrm{m}^{2}$ $(16,698 \%)$ (Gambar 2).

Di Kabiarat dengan jumlah 2 spesies, yaitu T. hemprichii dan E. acoroides dengan kepadatan tertinggi dimiliki oleh $T$. hemprichii dengan nilai kepadatan sebesar $27,05 \mathrm{ind} / \mathrm{m}^{2}(51,59 \%)$, kepadatan terendah dimiliki oleh $E$. acoroides dengan nilai kepadatan 25,38 ind $/ \mathrm{m}^{2}(48,41 \%)$ (Gambar 3$)$.

Di Watmasa dengan jumlah 5 spesies yaitu $H$. ovalis, $S$. isoetifolium, $T$. hemprichii, $H$. pinifolia dan $E$. acoroides. 
Spesies yang memiliki kepadatan tertinggi adalah $E$. acoroides dengan nilai kepadatan sebesar 64,05 ind $/ \mathrm{m}^{2}(50,48 \%)$, kepadatan terendah diiliki oleh $H$. ovalis dengan nilai $5,94 \mathrm{ind} / \mathrm{m}^{2}(4,68 \%)$ (Gambar 4).

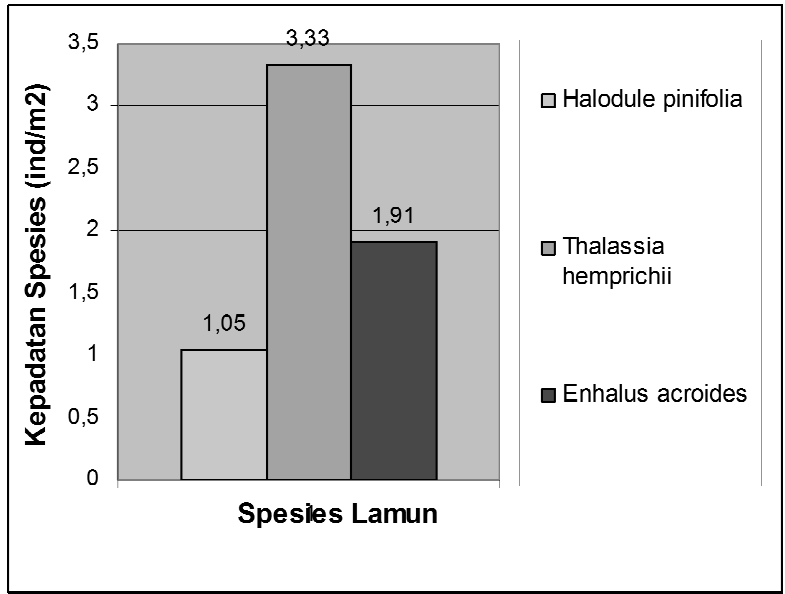

Gambar 2. Kepadatan jenis-jenis lamun di Lauran.

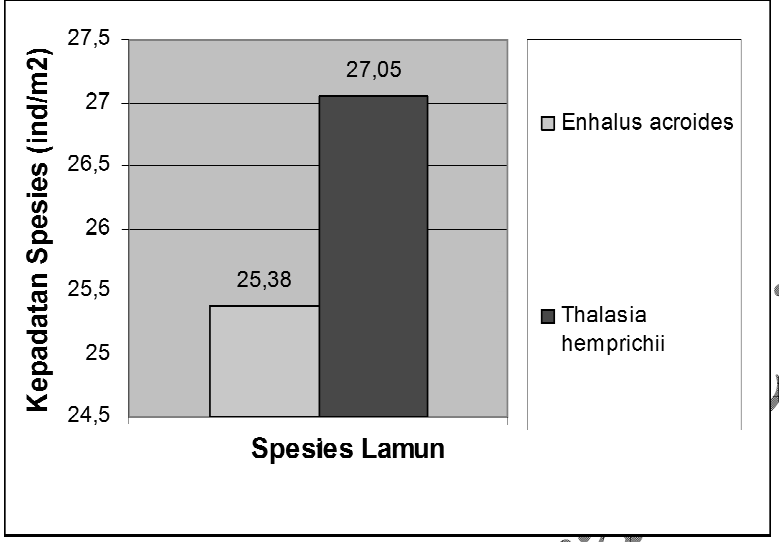

Gambar 3. Kepadatan jenis-jenis lamún dí Kabiarat.

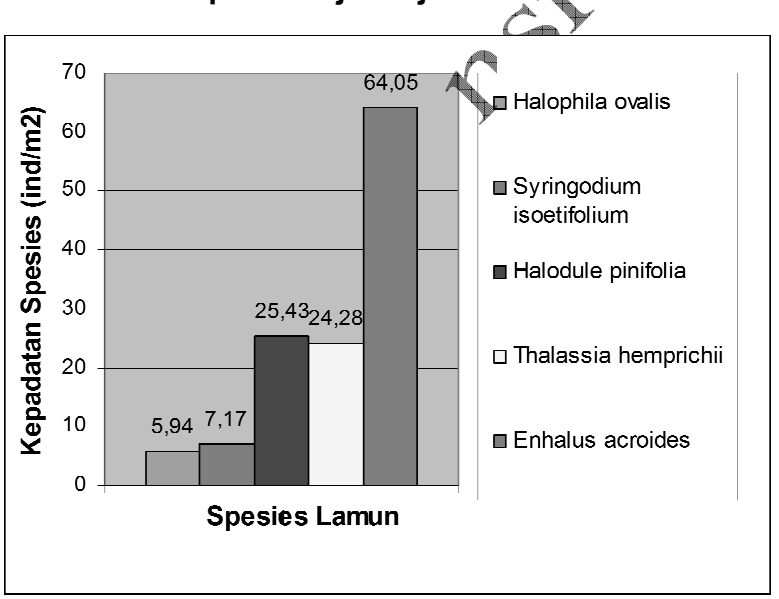

Gambar 4. Kepadatan jenis-jenis lamun di Watmasa.

Dari hasil analisis kapadatan jenisjenis lamun di setiap lokasi penelitian, jenis yang memiliki kepadatan tertinggi yaitu $E$. acoroides, C. rotundata, dan $T$. hemprichii. Hal ini diduga oleh kemampuan hidup jenis ini pada substrat yang cocok dan mampu beradaptasi dengan kondisi lingkungan yang ada sehingga memungkinkan spesiesspesies ini tumbuh. Untuk jenis yang memiliki kepadatan terendah yaitu $C$. rotundata, $H$. pinifolia, dan $H$. ovalis, kepadatan yang rendah diduga disebabkan oleh kondisi habitat yang kurang sesuai, kurangnya kemampuan berkompetisi dan kurangnya kemampuan untuk beradaptasi dengan lingkungan habitat yang ada.

\section{Kelimpahan Spesies Lamun}

Berdasarkan hasil analisis kelimpahan lamun di Olilit menunjukkan bahwa spesies yang memiliki kelimṕahan tertinggi adalah $C$. rotundata dengan nilai kelimpahan sebesar $27,75 \mathrm{ind} / \mathrm{m}^{2}(29,96 \%)$, sedangkan kelimpahan terenah dimiliki oleh $C$. serrulata dengan nilar, $/, 32$ ind $/ \mathrm{m}^{2}(7,11 \%)$ (Gambar 5).

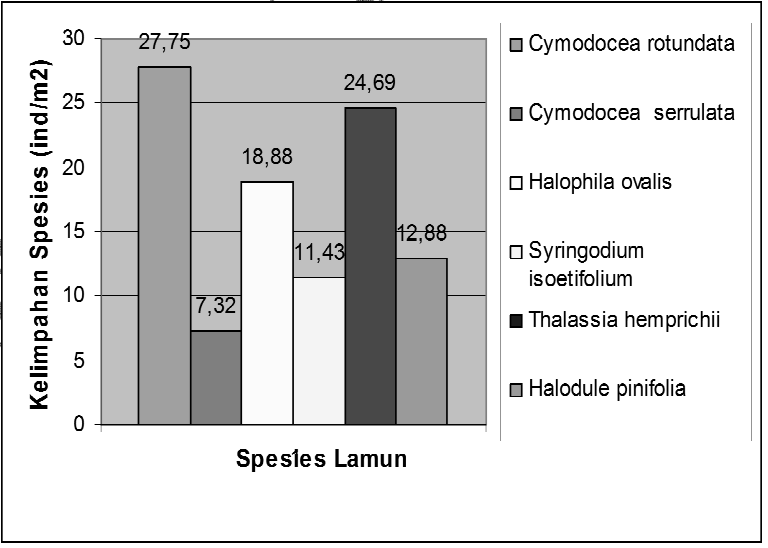

Gambar 5. Kelimpahan jenis-jenis lamun di Olilit.

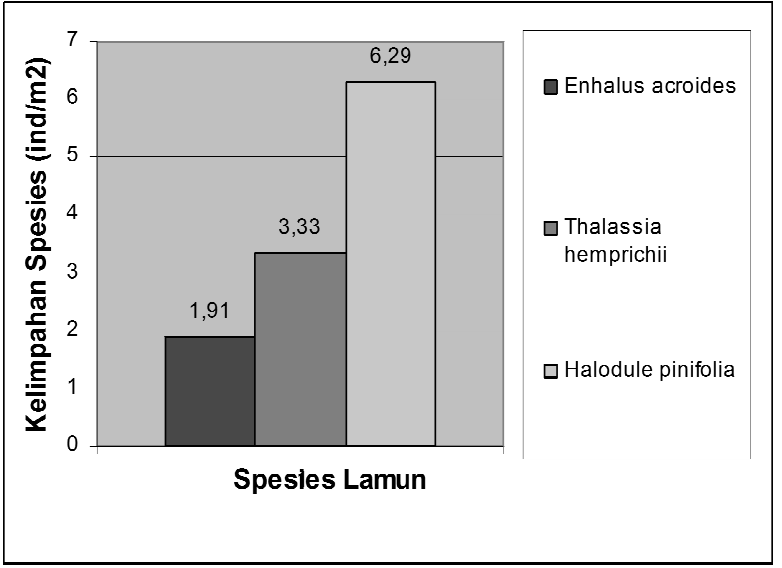

Gambar 6. Kelimpahan jenis-jenis lamun di Lauran.

Berdasarkan hasil analisis kelimpahan lamun di Lauran, spesies yang memiliki kelimpahan tertinggi adalah $H$. pinifolia dengan nilai kelimpahan sebesar 6,29 ind $/ \mathrm{m}^{2}(53,02 \%)$, sedangkan kelimpahan te- 
rendah dimiliki oleh $E$. acoroides dengan nilai $1,91 \mathrm{ind} / \mathrm{m}^{2}(16,69 \%)$ (Gambar 6$)$.

Hasil analisis kelimpahan lamun di Kabiarat menunjukkan bahwa spesies yang memiliki kelimpahan tertinggi adalah $T$. hemprichii dengan nilai kelimpahan sebesar $27,05 \mathrm{ind} / \mathrm{m}^{2} \quad(51,59 \%)$, kelimpahan terendah dimiliki oleh $E$. acoroides dengan nilai $25,38 \mathrm{ind} / \mathrm{m}^{2}(48,41 \%)$ (Gambar 7$)$.

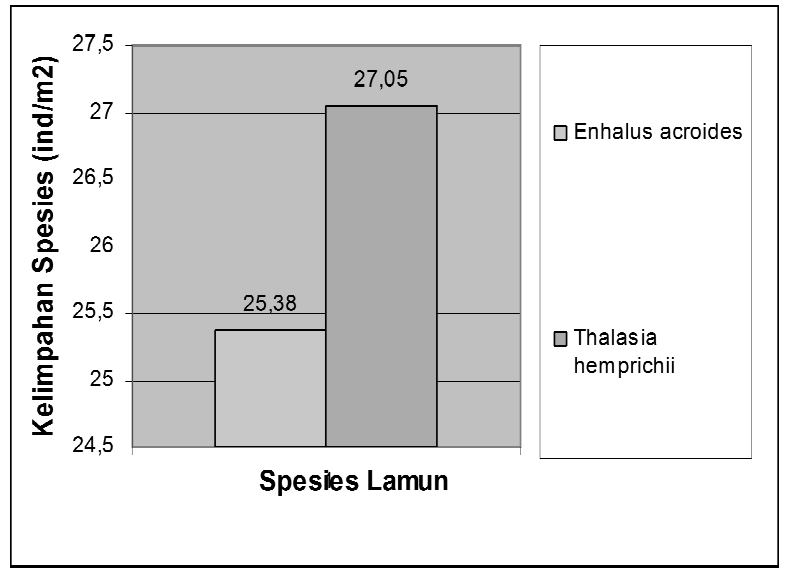

Gambar 7. Kelimpahan jenis-jenis lamun Kabiarat.

Hasil analisis kelimpahan lamun di Watmasa menunjukkan bahwa spesies yang memiliki kelimpahan tertinggi adalah $E$. acoroides dengan nilai kelimpahan sebesar $64,05 \mathrm{ind} / \mathrm{m}^{2}(50,48 \%)$, kelimpahan terendah dimiliki oleh $H$. ovalis dengan nilai. $5,94 \mathrm{ind} / \mathrm{m}^{2}(4,68 \%)$ (Gambar 8$)$.

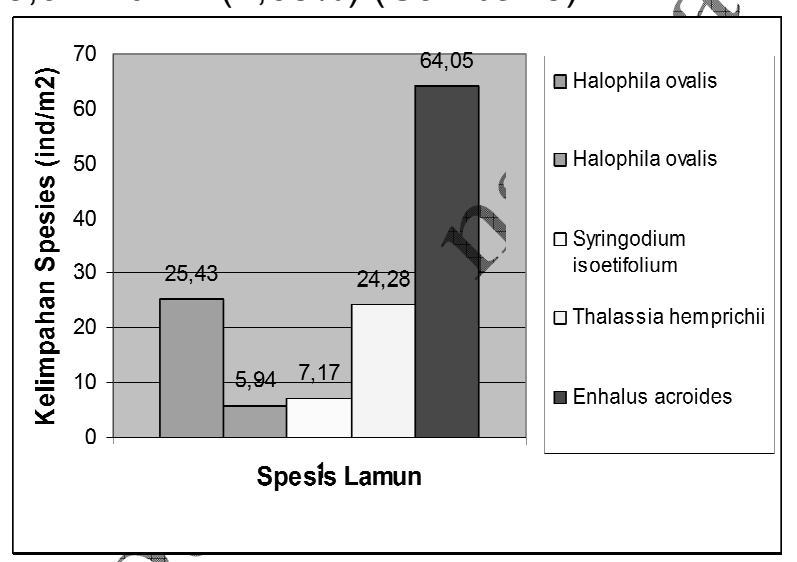

Gambar 8. Kelimpahan jenis-jenis lamun di Watsama.

\section{Frekuensi Kehadiran Lamun}

Berdasarkan hasil analisis frekuensi kehadiran di Olilit spesies yang memiliki frekuensi kehadiran tertinggi adalah $C$. rotundata dengan nilai frekuensi kehadiran sebesar $0,67 \mathrm{ind} / \mathrm{m}^{2}(19,42 \%)$, frekuensi kehadiran terendah dimiliki oleh $C$. serrulata dengan nilai $0,47 \mathrm{ind} / \mathrm{m}^{2}(13,59 \%)$ (Gambar 9).

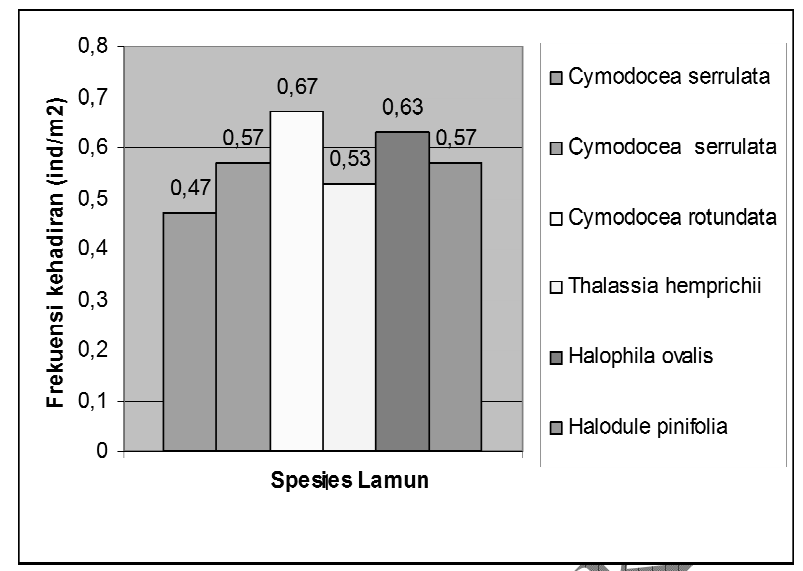

Gambar 9. Frekuensi kehadiran jenis-jenis lamun di Olilit.

Berdasarkan hasil lanalisis frekuensi kehadiran pada lokasi Lauran, spesies yang memiliki frekuensi kehadiran tertinggi adalah E. acroides dan $T$. hemprichii dengan nilai frekuensi kehadiran sebesar $0,7 \mathrm{ind} / \mathrm{m}^{2}(33,87 \%)$, frekuensi kehadiran terendah dimiliki oleh $H$. pinifolia dengan nilai $0,67 \mathrm{ind} / \mathrm{m}^{2}(32,26 \%)$ (Gambar 10$)$.

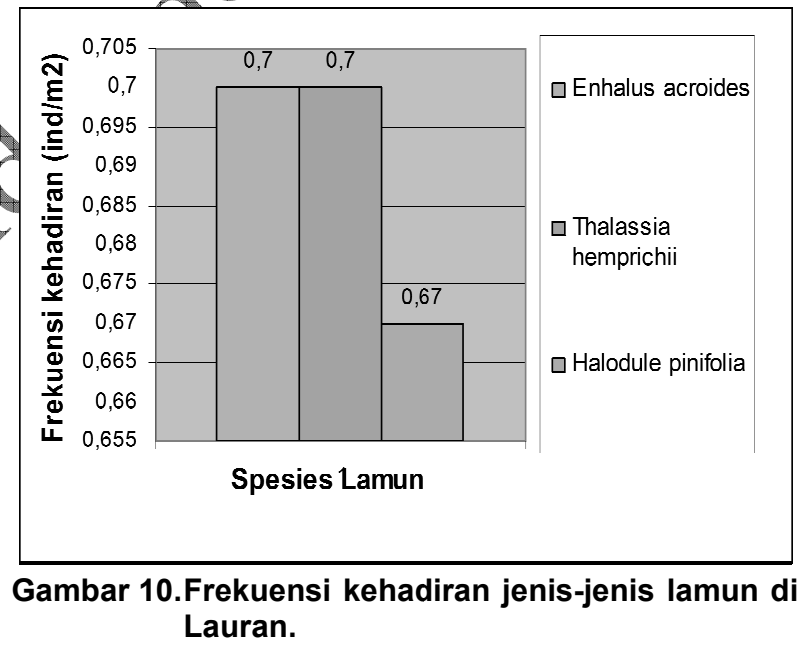

Berdasarkan hasil analisis frekuensi kehadiran di Kabiarat bahwa spesies yang memiliki frekuensi kehadiran tertinggi adalah $T$. hemprichii dengan nilai frekuensi kehadiran sebesar $0,52 \mathrm{ind} / \mathrm{m}^{2}(51,59 \%)$, frekuensi kehadiran terendah dimiliki oleh $E$. acoroides dengan nilai $0,48 \mathrm{ind} / \mathrm{m}^{2}$ $(48,41 \%)$ (Gambar 11).

Berdasarkan hasil analisis frekuensi kehadiran di Watmasa, spesies yang memiliki frekuensi kehadiran tertinggi adalah $H$. pinifolia dan $H$. ovalis dengan nilai frekuensi kehadiran sebesar $0,7 \mathrm{ind} / \mathrm{m}^{2}(21,43 \%)$, frekuensi kehadiran terendah dimiliki oleh $S$. isoetifolium dan $T$. hemprichii dengan nilai $0,6 \mathrm{ind} / \mathrm{m}^{2}(18,36 \%)$ (Gambar 12$)$. 


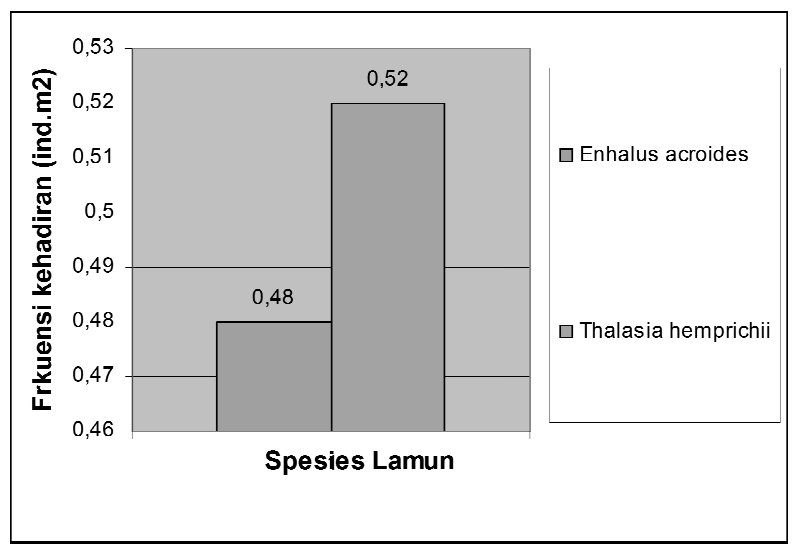

Gambar 11.Frekuensi kehadiran jenis-jenis lamun di Kabiarat.

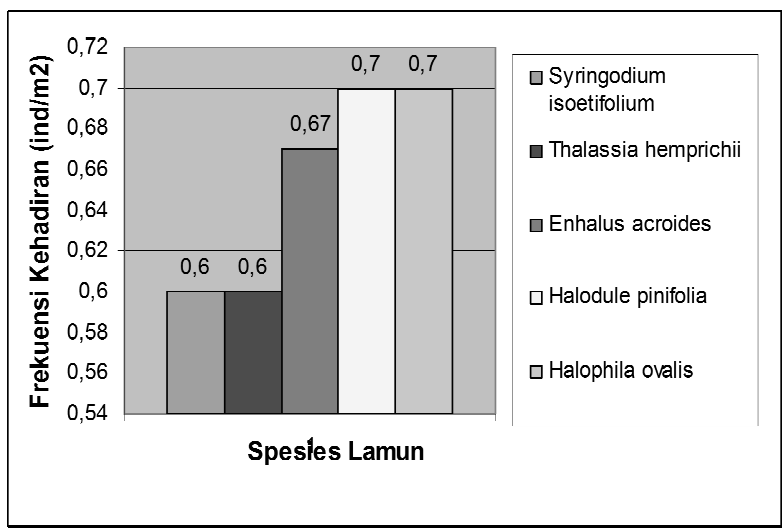

Gambar 12.Frekuensi kehadiran jenis-jenis lamun $d$ Watmasa.

Berdasarkan hasil penelitian yang ditemukan pada perairan Pulau Yamdeha secara keseluruhan, frekuensi Kéhadiran tertinggi yaitu $E$. acroides dan $T$. hemprichii, $H$. pinifolia dan IH. ovalis. Keadaan ini berarti bahwa spesies-spesies alga makro ini sering mucrl dalam setiap unit pengamatan. Sebaliknya spesies yang memiliki frekuensi kehadiran terendah yaitu C. serrulata. Hakin menunjukkan bahwa spesies lamun tersebut jarang muncul dalam setiap kotak pengamatan.

\section{KESIMPULAN}

Berdasarkan hasil penelitian dari keempat Yokasi penelitian dapat disimpulkan beberapa hal sebagai berikut:

1. Spesies-spesies lamun di Olilit, Lauran, Kabiarat, dan Watmasa teridentifikasi sebanyak 7 spesies yaitu Enhalus acoroides, Halophila ovalis, Halodule pinifolia, Thalassia hemprichii, Syringodium isoetifolium, Cymodocea rotundata dan Cymodocea serrulata.

2. Lamun yang ditemukan di Olilit sebanyak 6 spesies, di Lauran 3 spesies, di Kabiarat 2 spesies, dan di Watmasa 5 spesies. Hasil analisis kepadatan spesies lamun yang terdapat di lokasi penelitian, maka $C$. rotundata memiliki nilai kepadatan tertinggi di plilit, $T$. hemprichii di Lauran dan Kábiarat, $E$. acoroides di Kabiarat dan Wátmasa. Kelimpahan tertinggi di Olitit yakni $C$. rotundata, di Lauran H.J pinifolia, di Kabiarat $T$. hemprichii, di Watmasa $E$. acoroides. Untuk frekuensi kehadiran tertinggi yaitu Co fotundata di Olilit, $E$. acroides di Lauran, $T$. hemprichii di Kabiarat dan Laurán, dan $H$. pinifolia dan $H$. ovalis di Watmasa.

\section{OAAFTAR PUSTAKA}

Dahuutr, R., J. Rais., S.P. Ginting dan M.J. Sitepu 1996. Pengelolaan Wilayah Pesisir dan Lautan Secara Terpadu. PT. Pradya Paramita. Jakarta. 299 hal.

Den Hartog, C. 1970. The Seagrasses of The World. Nort Holland Publishing Company. Amsterdam.

Krebs, C.J. 1999. Ecological Methodology. Second Edition. Addison Wesley Longman, Inc. New York.

Nybakken, J.W. 1992. Biologi Laut. Suatu Pendekatan Ekologi. PT. Gramedia Pustaka Utama. Jakarta. 367 hal

Ongkers, O.T.S. 1990. Studi Kelimpahan Ikan Padang Lamun Tanjung Tiram Teluk Ambon Bagian Dalam. Tesis. Program Pascasarjana Institut Pertanian Bogor. Bogor. 